\title{
STUDY ON ENHANCEMENT OF OSSEOINTEGRATION OF THE BIO-ACTIVE TITANIUM IMPLANT BY LOW INTENSIVE ULTRASOUND WAVE
}

\author{
( Part I : Simulated Body Fluid soaking Test ) \\ Masanori Kobayahsi ${ }^{1}$ \\ ${ }^{1}$ Department of Physical Therapy, \\ Takarazuka University of Medical and Health Care, \\ Hyogo, Japan.
}

\begin{abstract}
In present study, the effect of the ultrasound wave stimulation in acceleration of the osteocondutibity of bioactive pure titanium was investigated. Pure titanium (99.9\% Ti) processed in chemical and heat treatments was used as a specimen, and soaked in simulated body fluid (SBF) under pulsed ultrasound wave for the planned time periods. The surface of samples was observed using scanning electron microscopy (SEM), Xray diffraction, etc, to assess the state of hydroxyapatite formation.SEM images showed that a richer and finer layer of calcium and phosphate compounds covered the titanium surface in the ultrasound wave group as compared with the non-ultrasound group. The measurements of mass of specimens also indicated the efficiency of ultrasound waves for hydroxyapatite formation. These findings suggest that the nucleation and crystallization of apatite on bio-active material surfaces might be promoted by micro-moving and cavitation of low-intensity pulsed ultrasound waves. We propose that pulsed ultrasound stimulation has a great potential for further improvement of osteointegration and osteoconductivity for medical bio-active implants.
\end{abstract}

\section{KEYWORDS}

Bio-active titanium, The low-intensity pulsed ultrasound waves, Osseointegration, Simulated Body Fluid (SBF), Hydroxyapatite

\section{INTRODUCTION}

It is well known that titanium and its alloys have excellent biocompatibility and mechanical properties, and have been widely used as medical implants under load-bearing conditions for dental and orthopedic fields. Since "Osseointegration" was first defined as a direct contact between living bone and the surface of a load-carrying implant at the histological level by Brånemark et al., this concept of bone bonding ability has required from the view of the postoperative therapeutics and rehabilitations [1-4]. Much has been learned about this concept and significant improvements on the design and surface of titanium implants were done to eliminate the important challenges of the implant dentistry and orthopedics surgery. [5-8]

Recently, bio-active titanium, which possesses an sufficient osseointegration, bone-bonding ability, has been developed by being exposed to a sodium hydroxide solution and heat treatment. This surface-modified titanium and its alloy are expected to be useful in clinical application as artificial joints and dental implants, etc $[9,10]$.

DOI: 10.5121/ijbes.2017.4401 
International Journal of Biomedical Engineering and Science (IJBES), Vol. 4, No. 4, October 2017

However, compared with natural bone tissue, other bio-active ceramics such as hydroxyapatite, the ability of osseointegration of this bio-active titanium is still inferior. Considering the clinical view, early bonding between implant and bone will accelerate the onset of activity of patients soon after an operation, with subsequent good long-term results. Therefore, some approach has been tried to accelerate more early bone bonding in this bio-active titanium $[11,12]$.

On the other hand, to enhance the osteogenesis and endogenous healing of bone fracture, low-intensity pulsed ultrasound stimulation has been used in the orthopedics surgery field [13-16]. Moreover, the studies in metal engineering field that the ultrasound stimulation could accelerate the crystallization of metallic glasses have been reported recently. Thus, we attempted to enhance the osseointegration or direct bone-bonding ability of bioactive titanium due to the induce of hydroxyapatite formation on the surface using the pulsed ultrasound radiation.

In the present study, we investigate whether the low-intensity pulsed ultrasound waves could accelerate the osseointegration of bio-active titanium in the experiment by the simulated body fluid (SBF) .

\section{MATERIAL AND METHOD}

The following formatting rules must be followed strictly. This (.doc) document may be used as a template for papers prepared using Microsoft Word. Papers not conforming to these requirements may not be published in the conference proceedings.

\subsection{The preparation of Bio-active titanium}

In the present study, in order to evaluate the effect of ultrasound pulsed radiating to the bone-bonding ability of two kinds of bio-active titanium, (the pure bioactive titanium and titanium alloy) specimen were prepared according to a following procedure.

Briefly, samples of pure titanium ( $99.9 \% \mathrm{Ti}$; Daido steel Co. Japan ) and titanium alloy $(\alpha+\beta$-Ti-6Al-4V ; Daido steel Co. Japan) were cut into $3 \mathrm{~mm} \times 3 \mathrm{~mm} \times 3 \mathrm{~mm}$ cubic dice, polished and chemically treated with $\mathrm{NaOH}$ solution (concentration:2M/1) for 2 hours reaction time. After that, these samples were heated at $600{ }^{\circ} \mathrm{C}$ for 1 hour in an electric furnace and then cooled to room temperature in the furnace for 24 hours to modify the surface.

Fig.1 shows the SEM images of pure titanium surface modified by chemical and heat treatment. The high magnification surface presents the porous meshed structure, which is correspond to the reports of the bio-active titanium surface by Kokubo et. al.[17]. It is speculated that these surface is composed of titanium oxide from the results of their study. 

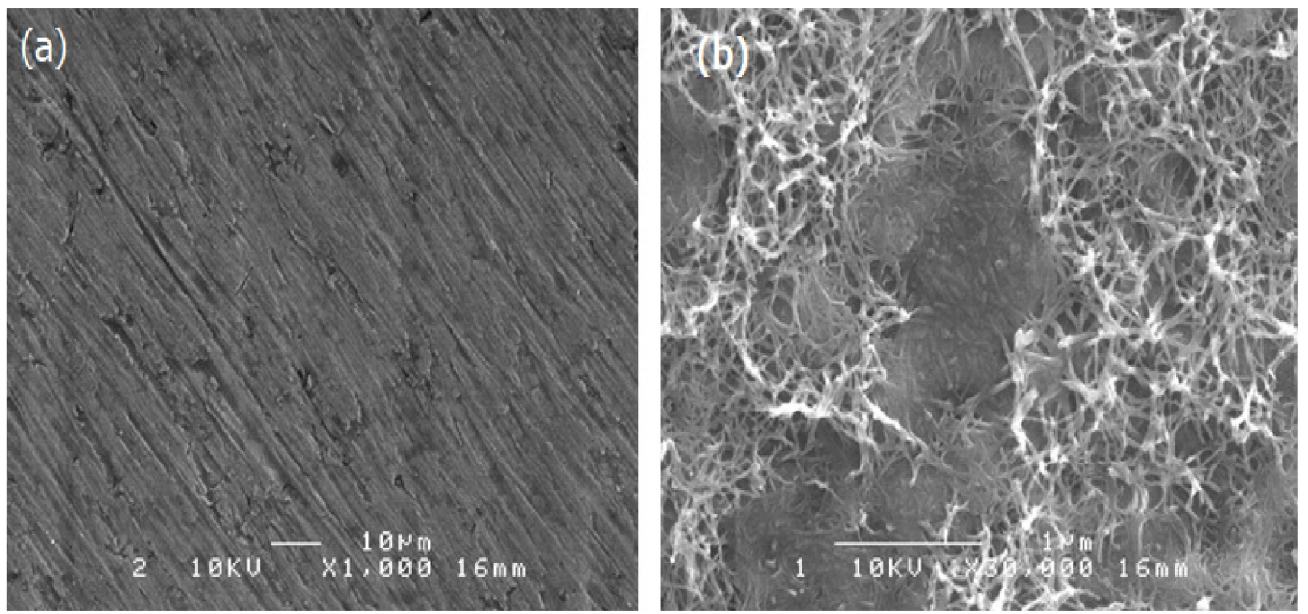

Figure.1 The SEM images of the surface of pure titanium specimens modified by chemical and heat treatment. ( (a) $\times 1000$ (b) $\times 3000)$ High magnification shows the porous structure composed of titanium oxide ( Titania )

\subsection{Methods}

As a basic bone-bonding ability test, the simulated body fluid (SBF) soaking method was performed as a simulation experiment according to Kokubo's studies in order to evaluate the apatite-forming ability of bio-active titanium and Bio-glass ceramics [2,18,19]. Hank's balanced solution ( $®$ Lonza; USA ) was used as a SBF solution, and maintained at $\mathrm{pH}$ over 7.0 and $37^{\circ} \mathrm{C}$ and replaced every two days.

Ultrasound radiation was applied by using Sonic Accelerated Fracture Healing System (SAFHS; Smith \& Nephew, Memphis, TN, USA ; Teijin Pharma, Tokyo, Japan ). The treatment head module delivered ultrasound waves with $1.5 \mathrm{~Hz}$ sine waves, $200 \mu \mathrm{sec}$ signal term, and spatial average intensity of $30 \mathrm{~mW} / \mathrm{cm} 2$.

Pure titanium and titanium alloy samples were soaked in SBF and subjected to ultrasound stimulation for $20 \mathrm{~min}$ daily during the operation term for three days, one week, and two weeks, respectively. As a control, the same samples were left in SBF without ultrasound radiation under the same experimental conditions (Fig. 2).

After the above-mentioned processes were completed, the titanium sample surface was subjected to scanning electron microscopy (SEM), energy dispersive spectroscopy (EDS) and X-ray diffraction (XRD), and these analyses were focused on the top surfaces, on which the ultrasound wave was directly radiated. Furthermore, to compare with the effect of ultrasound waves, the change of the sample's mass before/after the SBF treatment was measured. 


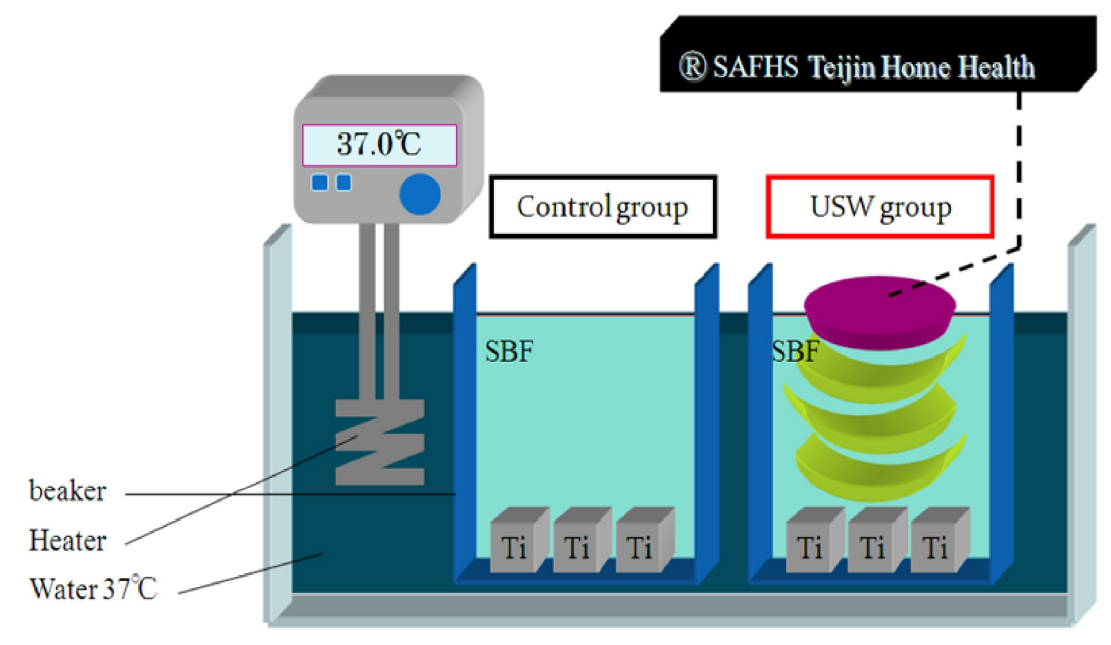

Figure.2 The schematic diagram of the pulsed ultrasound waving radiation on titanium specimens in SBF.

\section{RESULTS}

\subsection{SEM Observation}

Fig. 3 shows the SEM images of the texture on the pure titanium surface of the ultrasound wave group with radiation distance of $50 \mathrm{~mm}$ and control group.

(a)

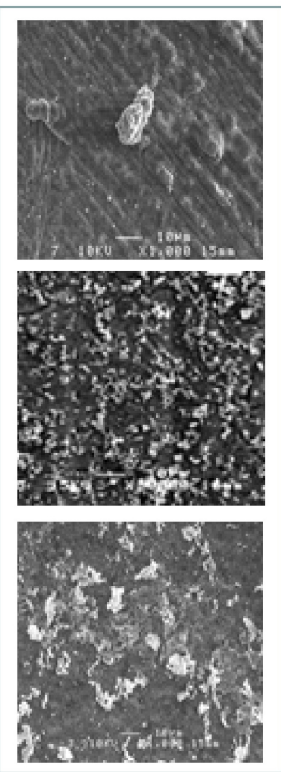

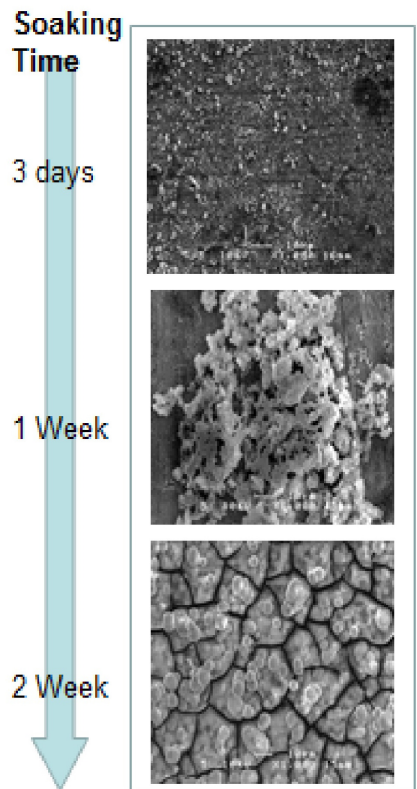

(b)

Figure.3 SEM micrographs of the surface of bio-active pure titanium specimen after soaking in SBF

(a) without ultrasound wave ( Control group) (b) using ultrasound wave $(\times 1000)$ 
International Journal of Biomedical Engineering and Science (IJBES), Vol. 4, No. 4, October 2017

In the immersion experiments for 3 days, the surfaces of the ultrasound wave group showed richer structure compared with the control group. Until one week, the morphology of the structure in the ultrasound wave group progressed to dendrite or needle-like crystalline structures, while the texture of the control group remained as small particles. By two weeks, the groups exhibited even greater differences in morphologies in terms of the crystallization on the substrates. The ultrasound wave group had changed into larger global grains, which indicates stable precipitate processes in terms of chemical equilibrium.

Fig.4 shows the SEM images of the texture on the titanium alloy specimen surface of the ultrasound wave group with radiation distance of $50 \mathrm{~mm}$ and control group. As well as the case of pure titanium specimens, the morphological change of the crystalline on the substrate surface showed more active progress and growth in the ultrasound wave radiation group.

(a)

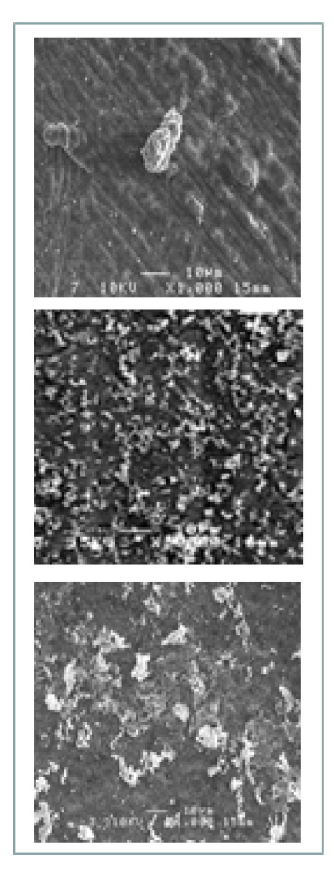

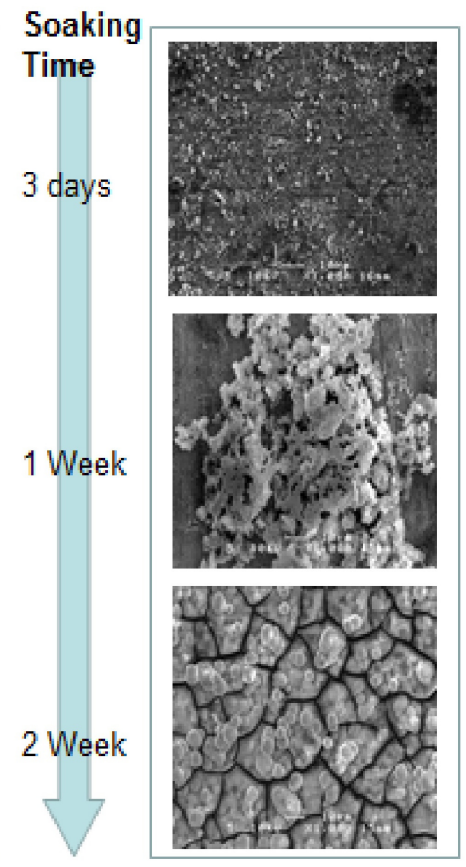

(b)

Figure.4 SEM micrographs of the surface of bio-active titanium alloy specimen after soaking in SBF (a) without ultrasound wave (Control group) (b) using ultrasound wave ( $\times 1000)$

\subsection{EDS analysis}

Fig. 5 and 6 compares the EDS spectra of two different areas on the titanium specimens' surface which were immersed in SBF for 2 weeks without ultrasound waving (control groups). 
International Journal of Biomedical Engineering and Science (IJBES), Vol. 4, No. 4, October 2017

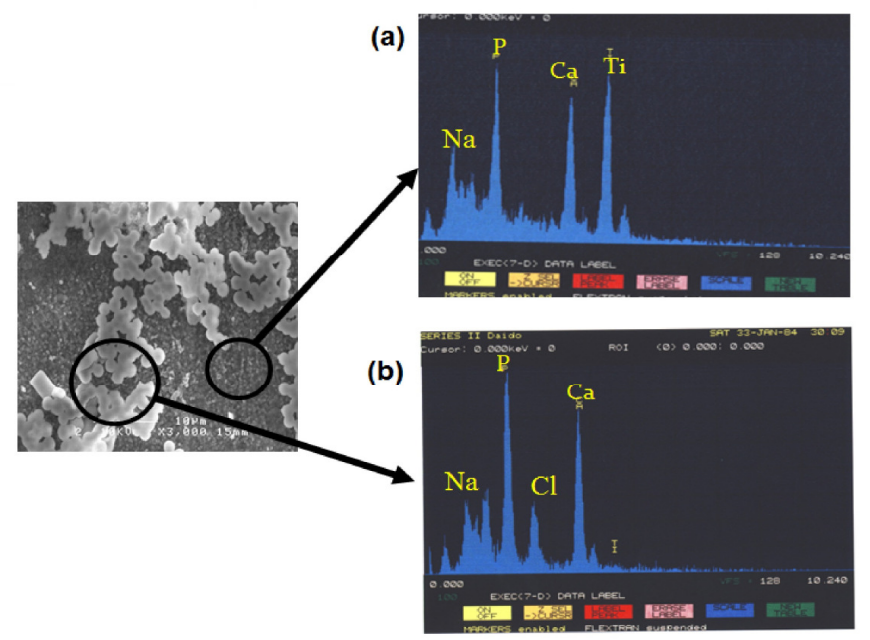

Figure.5 EDS analysis of bioactive pure titanium surface soaked in SBF for 2 weeks The based surface (b) The precipitation area

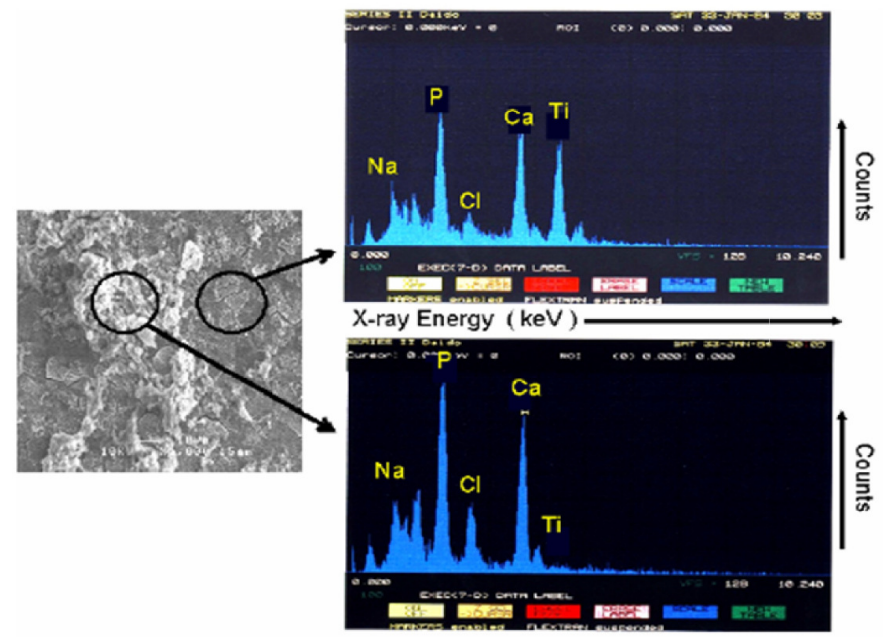

Fig.6 EDS analysis of bioactive titanium alloy surface soaked in SBF for 2 weeks (a) The based surface (b) The precipitation area

As shown in Fig.5(a) and 6 (a), Peaks of calcium and phosphorous can be seen in the deposition area, confirming the presence of calcium-phosphate on this structure, while higher titanium peak intensity was observed on the substrate titanium surface except the structure (Fig 5(b) and 6(b)). The pattern of spectra of both of pure titanium and titanium alloy group were observed no significant difference.

\subsection{XRD analysis}

The XRD patterns of the crystalline substances on the titanium surface after one week of two groups are shown in Fig. 7. Though the typical XRD pattern of hydroxyapatite was not observed, some peaks of hydroxyapatite were observed. 
International Journal of Biomedical Engineering and Science (IJBES), Vol. 4, No. 4, October 2017

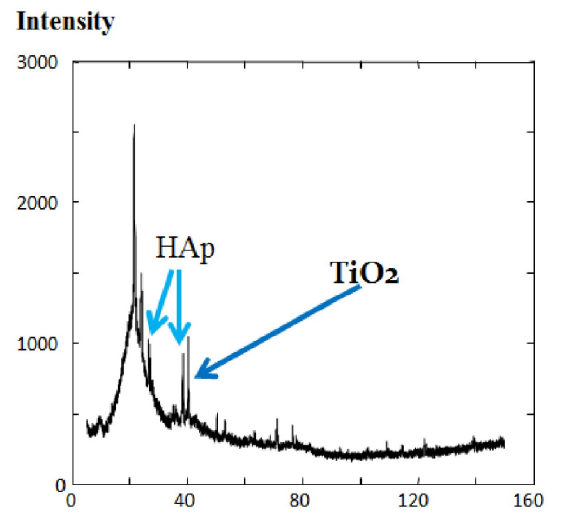

(a)
Intensity

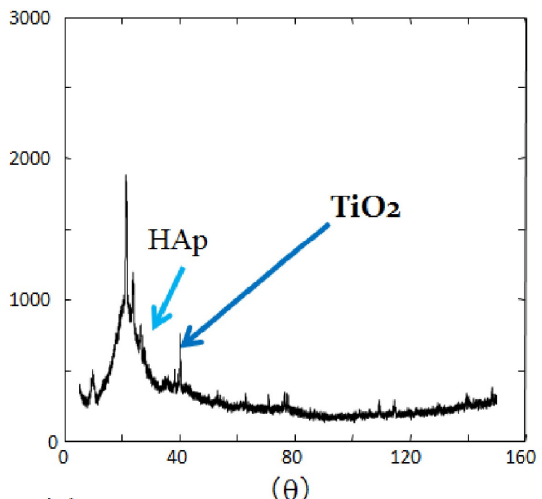

(b)

Figure. 7 XRD of specimen soaking in SBF for 1 week under the ultrasound irradiation
(a) Pure Titanium
(b) Titanium alloy

Considering the existence of a calcium-phosphate crystalline coating confirmed by the EDS spectra, these data suggested a series of chemical processes in which the calcium and phosphorous ions were adsorbed and deposited onto the bio-active titanium surface, and then transformed from calcium phosphate into crystalline of hydroxyapatite.

\subsection{Measurement of the mass of Ca-P Crystallization}

Fig. 8 shows the measured sample mass change before/after the SBF treatment as a hydroxyapatite-like precipitation. In both of pure titanium and titanium alloy materials, the ultrasound wave radiated titanium showed significant increases of substrates as compared with the control group according to SBF soaking times $(\mathrm{p}<0.05)$. Unshown in this figure, other radiating distances specimens $(10 \mathrm{~mm}, 30 \mathrm{~mm})$ also exhibited same curves of precipitation mass.

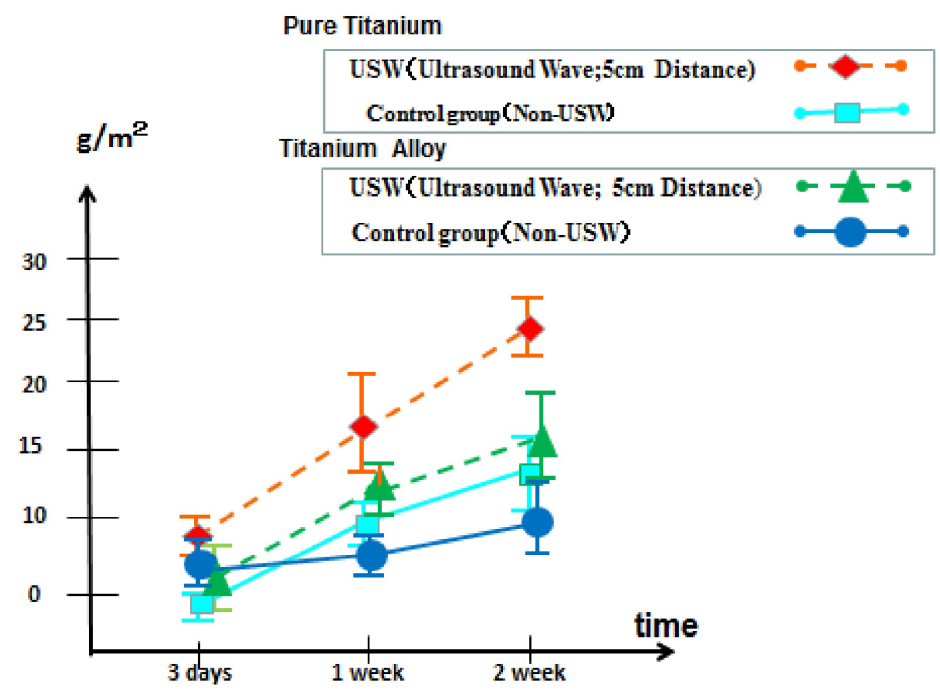

Figure.8 Soaking time dependence of mass of $\mathrm{P} / \mathrm{Ca}$ precipitation formation on titanium specimen's surface 
International Journal of Biomedical Engineering and Science (IJBES), Vol. 4, No. 4, October 2017

As comparison between two kinds of materials, pure titanium and titanium alloy, this measurement indicated the superiority of the hydroxyapatite-like precipitation of pure titanium.

\section{DISCUSSION}

The simulation method using SBF soaking in this study is well known as a in vitro assay for evaluation of bone-bonding ability of biomaterials, and has been already used widely for the study regarding the osteoconductivity [18-20 ].According to Kokubo who have developed the bio-active titanium, the mechanism of bone-like apatite formation on bio-active titanium was as follows: the activated sodium titanium hydrogel or amorphous sodium titanate layer are formed on the surface of titanium and its alloy by $\mathrm{NaOH}$ and subsequent heat treatment. This surface layer with a thickness $1 \mu \mathrm{m}$ has a fine network structure, when this titanium is soaked in SBF, the nucleation and growth of calcium phosphate compounds from SBF occur on this surface layer. In vivo, this bone-like apatite formation on bio-active titanium surface will secondary progress the process of the biological bonding to natural bone tissue. Therefore, the in vivo bone-bonding ability of bio-active titanium is depend on the apatite formation on the surface. In fact, it has been already confirmed that in vitro results in SBF concerning the bone-bonding ability of bioactive titanium correspondent to the results for osteointegration in vivo [2,20].

As a result, the increasing of calcium-phosphate precipitation including partial hydroxyapatite crystalline by ultrasound wave irradiation was confirmed. Morphological observation by SEM in the early phase of SBF soaking exhibited more nuclei on the titanium surface in the USW group than in the control group. This finding implies that the enhanced crystallization process due to the influence of ultrasound waves occurs at the initial state of nucleation and growth of calcium phosphate compounds. The microstructural feature of accelerated calcium-phosphate crystalline at 1 week under the USW showed branch-like morphology, i.e. the dendrite type, which indicates rapid crystalline formation under poor latent heat transfer [21,22]. This fact indicated that the partial concentration and interatomic potential of the $\mathrm{Ca}$ and $\mathrm{PO} 4$ ions in SBF can be changed by ultrasound micro vibration, and accelerated to the nucleation and deposition of ions, resulting in the crystallization of calcium phosphate on activated titanium surface layer. Cavitation by ultrasound waves might also contribute to formation of the apatite layer by means of the microfracture of calcium-phosphate and the circulation of new $\mathrm{Ca}$ and PO4 ions of SBF on the titanium surface. These environmental changes will accelerate further changes of interatomic potential of surrounding atoms, and deteriorate the thermal stability of calcium-phosphate phase versus $\mathrm{Ca}$ and $\mathrm{PO} 4$ ions. Tanaka has already reported an increase of degrees of freedom and number of crystal orientations for atomic pileup by thermal vibration concerning the relationship between the dendritic crystal and ultrasound vibration [23]. According to his report, the rapid crystallization caused by ultrasound waves is considered to enhance the nucleation process rather than the growth stage. The same ultrasound-induced crystallization has been recently reported in the metallurgy field; however, the detailed mechanism is still unclear [24-26].

As comparison between the osseointegration of the two kinds of materials, pure titanium and titanium alloy, all data in this experiment indicated the superiority of pure titanium. Kokubo et. al. have already reported that pure bio-active titanium has more excellent osteoconductivity as compared with titanium alloy since pure titanium has more rich modified sodium titanium hydrogel layer, which is suitable for formation of the hydroxyapatite crystalline. Our result also suggested that the initial nucleation and 
International Journal of Biomedical Engineering and Science (IJBES), Vol. 4, No. 4, October 2017

deposition of calcium phosphate on activated titanium surface layer could be very important for the enhancement of the crystallization by ultrasound waving.

Although the mechanism of ultrasound waving irradiation could accelerate the secondary crystal growth of bone-like apatite are unclear, this result indicated the clinical application of ultrasound waving irradiation has potential for enhancement of osseointegration of bioactive titanium dental implant.

\section{REFERENCES}

[1] Ohnishi E, Fujibayashi S, Takemoto M, Neo M, Maruyama T, Kokubo T, Nakamura T. (2008) "Enhancement of bone-bonding ability of bioactive titanium by prostagrandin E2 receptor selective agonist.” Biomaterials ; Vol. 29, pp 877-883

[2] Kokubo T, Takamada H, (2006) "How useful is SBF in predicting in vivo bone bioactivity? " Biomaterials, Vol.27: pp 2907-15

[3] Brånemark, P.I.; Hansson, B.O.; Adell, R.; Breine, U.; Lindström, J.; Hallén, O. \& Ohman, . (1977) "Osseointegrated implants in the treatment of the edentulous jaw. Experience from a 10-year period." Scandinavian Journal of Plastic and Reconstructive Surgery. Supplementum, Vol.16, pp 1-132

[4] Brånemark, P.I. (1983) “ Osseointegration and its experimental background.” Journal of Prosthetic Dentistry. Vol.50 pp 399-410.

[5] Thomas KA, Kay JF, Cook SD, Jarcho M. (1987) "The effect of surface macrotexture and hydroxyapatite coating on the mechanical strength and histologic profiles of titanium implant materials.” J.Biomed.Mater.Res. Vol. 21, pp1395-1406

[6] De Andrade MD, Sader MS, Filgueiras MRT, Ogasawara T. (2000) “ Microstructure of ceramic coating on titanium surface as a result of hydrothermal treatment." J. Mater Sci : Mater Med. Vol. 11 , pp 751-55.

[7] Kawashita M, Itoh S, Miyamoto K, Takaoka GH. (2008) “ Apatite formation on titanium substrates by electrochemical deposition in metastable calcium phosphate solution.” J.Mater Sci : Mater Med. Vol. $19: 137-142$

[8] Ralf Smeets, Bernd Stadlinger, Frank Schwarz, Benedicta Beck-Broichsitter, Ole Jung, Clarissa Precht, Frank Kloss, Alexander Gröbe, Max Heiland, Tobias Ebker. (2016) “ Impact of Dental Implant Surface Modifications on Osseointegration” BioMed Research International. Pp 1-16.

[9] Kim HM, Kokubo T, Fujibayashi S, Nishiguchi S, Nakamura T. (2000) "Bioactive macroporous titanium surface layer on titanium substrate.” J. Biomed. Mater. Res. Vol. 52, pp 553-57.

[10] Nishiguchi S, Kokubo T, Miyaji F, Kim HM, Nakamura T. (1999) “ The effect of heat treatment on bone-bonding ability of alkali-treated titanium.” Biomaterials. Vol.20, pp 491-500.

[11] Fujibayashi S, Kokubo T, Miyaji F, Kim HM, Nakamura T. (2001) “ Bioactive titanium : effect of sodium removal on the bone-bonding ability of bioactive titanium prepared by alkali and heat treatment. ” J. Biomed. Mater. Res. Vol.56 pp 562-70.

[12] Onishi E, Fujibayashi S, Takemoto M, Neo M, Maruyama T, Kokubo T, Nakamura T. (2008) "Enhancement of bone-bonding ability of bioactive titanium by prostagrandin E2 receptor selective agonist." Biomaterials, Vol. 29, pp 877-883

[13] Heckman JD, Ryaby JP, McCabe J, Frey JJ, Kilcoyne RF. (1994) “ Acceleration of tibial fracturehealing by non-invasive, low intensity pulsed ultrasound.” J.Bone.Joint.Surg.(A) Vol. 76 , pp 2634. 
International Journal of Biomedical Engineering and Science (IJBES), Vol. 4, No. 4, October 2017

[14] Kristiansen TK, Ryaby JP, McCabe J, Frey JJ, Roe LR. (1997) “ Accelerated healing of distal radial fractures with the use of specific, low-intensity ultrasound. A multicenter, prospective, randomaized, double-blind, placebo-controlled study.” J.Bone.Joint.Surg.(A) Vol. 79 ,pp 961-73

[15] Tsumaki N, Kakiuchi M, Sasaki J, Ochi T, Yoshikawa H. (2004) “ Low-intensity pulsed ultrasound accelerates maturation of callus in patients treated with opening-wedge high tibial osteotomy by hemicallotasis." J.Bone.Joint.Surg.(A), Vol. 86 , pp 2399-2405

[16] Yang K.H, Park SJ. (2001) “ Stimulation of fracture healing in a canine ulna full-defect model by low-intensity pulsed ultrasound.” Yonsei.Med.J. Vol. 42 pp 503-508.

[17] Kokubo T, Miyaji F, Kim HM, Nakamura T. Spontaneous formation of bonelike apatite layer on chemically treated titanium metals. J. Am. Cerami. Soc. 1996 ; 79 : 1127-1129.

[18] Kokubo T, Yamaguchi S. (2010) "Novel Bioactive Titanate Layers Formed on Ti Metal and Its Alloy by Chemical Treatments." Materials Vol. 3 pp.48-63.

[19] Nishiguchi S, Fujibayashi S, Kim HM, Kokubo T, Nakamura T. (2003) "Biology of alkali- and heattreated titanium implants." Journal of Biomedical Material Research A, Vol.67, pp.26-35

[20] Kim H.M, Miyaji F, Kokubo T, Nakamura T. (1996) "Preparation of bioactive Ti and its alloys via simple chemical surface treatment.” J. Biomed. Mater. Res. Vol.32 , pp 409-17.

[21] Hurle D. T. J., (1993) "Handbook of crystal growth 1b," North Holland.

[22] Teraoka Y, Saito A, Okawa S. (2002) "Ice crystal growth in supercooled solution" Int. J .Refrigeration, Vol. 25, pp 218-225.

[23] Tanaka A, Sawada K. (1989) "The Effect of the Pulse ultrasonic waves in the dendritic crystal growth.” Bussei.Kenkyu. Vol. 52, pp 430-434. ( in Japanese )

[24] Ichitsubo T, Matsubara E, Kai S, Hirano M. (2004) "Ultrasound-induced crystallization around the glass transition temperature for Pd40Ni40P20 metallic glass.” Acta.Mate. Vol. 52 , pp 423-429

[25] Ichitsubo T, Matsubara E, Anazawa K, Nishiyama N, Naito M, Hirotsu Y. (2006) " Low-temperature crystallization caused by ultrasound in Pd42.5Ni7.5Cu30P20 and Pd40Ni40P20 bulk metallic glasses." Mate.Sci.Eng. A442, pp 273-277.

[26] Ichitsubo T, Matsubara E, Anazawa K, Nishiyama N. (2007) "Crystallization accelerated by ultrasound in Pd-based metallic glasses.” J. Alloy.Compounds. Vol. 434-435, pp 194-5. 